\title{
Cytoreductive surgery and heated intrathoracic chemotherapy for thoracic extension of Pseudomyxoma peritonei
}

\author{
Mathew P. Doyle ${ }^{1,2 *}$, Claudia I. Villanueva ${ }^{1,3}$, Samuel Davies ${ }^{2}$, Gary G. Fermanis ${ }^{1,3}$, Matthew D. Horton ${ }^{1,3}$ and David L. Morris ${ }^{3,4}$ \\ ${ }^{1}$ Department of Cardiothoracic Surgery, St George Hospital, Kogarah, Australia \\ ${ }^{2}$ Graduate School of Medicine, University of Wollongong, Wollongong, Australia \\ ${ }^{3}$ School of Medicine, University of New South Wales, Sydney, Australia \\ ${ }^{4}$ Department of Surgery, University of New South Wales, St George Hospital, Kogarah, Australia
}

\begin{abstract}
Background: Thoracic extension of Pseudomyxoma peritonei can occur via trans-diaphragmatic spread of abdominal disease. Cytoreductive surgery with intraoperative intrapleural chemotherapy may prolong survival in an otherwise terminal condition. We evaluate the long-term outcomes of patients undergoing thoracic cytoreductive surgery and intrathoracic intraoperative chemotherapy for pleural extension of Pseudomyxoma peritonei.

Methods: All patients who underwent thoracic cytoreductive surgery and heated intrathoracic chemotherapy for thoracic spread of PMP were identified from our prospectively compiled registry. Peri operative outcomes were reviewed and long term results were obtained from follow up and correspondence from other specialists. Long-term mortality was calculated from follow-up data.

Results: There were three men and three women. The median age at thoracic surgery was 49.7 years. All patients had undergone previous abdominal surgery for pseudomyxoma. Time from initial cytoreductive surgery to thoracic recurrence ranged from 12.1 to 135 months. There was no perioperative mortality. Follow up range was $8-132$ months. There were no cases of thoracic disease recurrence following complete thoracic cytoreduction. 5 and 10 -year survival was $80 \%$ and $40 \%$ respectively.

Conclusions: Complete cytoreduction and heated intrathoracic intraoperative chemotherapy can provide long-term disease free and overall survival for patients with thoracic recurrence of pseudomyxoma peritonei.
\end{abstract}

\section{Introduction}

Intrathoracic spread of pseudomyxoma peritonei (PMP) occurs after the mucinous ascites of PMP accesses the thoracic cavity. The original tumour is an epithelial mucinous tumour of the appendix that grows until the lumen becomes obstructed and ruptures, spilling mucin-producing cells into the abdomen. The progressive deposition of the mucinous ascites can lead to local organ compression, causing the usual presenting symptoms of abdominal distension, abdominal mass or intestinal obstruction. PMP was once considered an endstage disease, with palliative treatments such as debulking surgery and systemic chemotherapy aimed at reducing gross tumour burden and symptom relief. Specialised centres now perform cytoreductive surgery (CRS) with intraoperative loco-regional chemotherapy with the aim of complete macro- and microscopic tumour eradication. CRS with heated intraperitoneal chemotherapy (HIPEC) has demonstrated survival benefits for PMP from both high grade (peritoneal mucinous carcinomatosis - PMCA) and low-grade (disseminated peritoneal adenomucinosis - DPAM) appendiceal tumours, although high-grade tumours carry a significantly worse prognosis than their low-grade counterparts. PMCA has a 5 year survival rate of less than $50 \%$ when treated with CRS and HIPEC [1-3], whilst DPAM has 5 year survival rates over $75 \%$ following the same treatment $[1,2,4,5]$.

The spread of PMP to the thoracic cavity is rare. Similar to
PMP, pleural dissemination of these mucin-producing cells can cause symptoms from local organ mass effects. Once the thoracoabdominal boundary of the diaphragm has been breached, the disease may continue to have insidious progress and cause symptoms from compression of local structures such as the lungs, heart, major vessels and other mediastinal structures. The intrathoracic spread of PMP is most often identified on surveillance imaging following previous abdominal CRS. Treatments including debulking surgery and systemic chemotherapy have been performed as palliative treatment options. Applying the same principles to the thorax as the abdomen, CRS and loco-regional intraoperative chemotherapy provides the potential for complete disease eradication for patients with intrathoracic spread of PMP. The use of CRS with and without heated intrathoracic chemotherapy (HITHOC) has been described for thoracic extension of PMP in small case series and single case reports only [6,7]. Early results from our institution have been reported previously in a series

Correspondence to: Mathew Doyle, Department of Cardiothoracic Surgery, St George Hospital, Kogarah, NSW, 2217. Australia, Tel: +61 29113 1111, Fax: +61 29113 2193, E-mail: drmathewdoyle@gmail.com

Key words: Pseudomyxoma peritonei, intra-pleural chemotherapy, intrathoracic chemotherapy, heated chemotherapy, cytoreduction

Received: May 11, 2016; Accepted: June 30, 2016; Published: July 03, 2016 
of patients who underwent thoracic CRS and HITHOC for PMP with intrathoracic extension [8]. This current study includes long-term outcomes for these patients.

\section{Patients and methods}

All patients with thoracic spread of PMP were identified from our prospectively compiled registry of patients with abdominal PMP. Histopathology reports were also checked to confirm the pathology treated at thoracic CRS was the same as previously identified from abdominal resection. Six patients from this series had intrathoracic extension of PMP identified on surveillance imaging. All patients had previously undergone CRS for PMP and had been referred to our centre for management of their recurrent PMP. A multidisciplinary team including a cardiothoracic surgeon, surgical oncologist, radiologist, medical oncologist and cancer care nurse reviewed each case prior to undergoing surgery.

Either pleurectomy or decortication (for pleural based spread), or parenchymal anatomic resections of the affected lobe or lung (for intra-parenchymal disease) were performed by a cardiothoracic surgeon. Each patient underwent postero-lateral thoracotomy and intraoperative assessment of the extent of the disease before a definitive surgical plan was formulated. Both surgical oncologist and cardiothoracic surgeon were present for the thoracic cytoreduction. Following adequate exposure of the thoracic cavity and affected lung, pleurectomy and decortication was performed. In cases of parenchymal involvement either on radiological or surgical operative assessment, anatomical resections of the involved lobe or lung was performed. Following maximal cytoreduction, heated intrathoracic chemotherapy (HITHOC) was infused into the pleural space. Mitomycin C was used for all cases, at a temperature of $41.5^{\circ} \mathrm{C}$.

Following drainage and lavage of the pleural space, assessment of the remaining intra-pleural structures was performed to ensure pneumo- and haemostasis. Two intercostal catheters were inserted (apical and basal) and the chest was closed in a routine fashion. All patients remained intubated and were transferred to the intensive care unit for postoperative care.

\section{Results}

From 1997 to 2014, 827 cytoreductive surgeries with HIPEC were performed at our centre. 191 had PMCA and 220 had DPAM. The outcomes of our institution's experience with CRS and HIPEC for PMP have recently been reported [2]. Six patients had intrathoracic recurrence of PMP. All had histologically-proven low-grade disease (DPAM). Three were men and three were women. The mean age at time of surgery was 49.7 years and the median age was 50.5 years. Five patients had disease present unilaterally and one patient had bilateral pleural disease. Three patients had pleural-based PMP only, with one patient having isolated pulmonary disease with no macroscopic pleural involvement. The characteristics of all patients are included in Table 1. One patient underwent radical pneumonectomy for complete encasement and obliteration of the lung by tumour. She is the only reported case of successful radical pneumonectomy for thoracic PMP in the current literature. Preoperative radiologic images (Figure 1) and intraoperative pictures (Figure 2) are included.

All patients had undergone previous abdominal CRS for PMP. Four patients had concomitant HIPEC at the time of their previous CRS. The time to pleural recurrence from initial CRS ranged from 12.1 to 135 months. At the time of thoracic CRS, all lymph node biopsies
Table 1. Characteristics of patients who underwent cytoreductive surgery and heated intrathoracic intraoperative chemotherapy for pleural recurrence of Pseudomyxoma peritonei.

\begin{tabular}{|c|c|c|}
\hline Total & & 6 \\
\hline Age at time of CRS + HITHOC & mean age (SD) & $49.7(12.7)$ \\
\hline \multirow{2}{*}{ Gender } & Male & 3 \\
\hline & Female & 3 \\
\hline \multirow{5}{*}{ Previous abdominal PMP } & Number & 6 \\
\hline & Previous abdominal CRS & 6 \\
\hline & Previous HIPEC & 4 \\
\hline & Redo abdominal CRS & 4 \\
\hline & Redo abdominal CRS + HIPEC & 2 \\
\hline \multirow{3}{*}{$\begin{array}{l}\text { Diaphragmatic involvement at } \\
\text { time of CRS + HIPEC }\end{array}$} & Number & 5 \\
\hline & Stripped & 3 \\
\hline & Perforated & 2 \\
\hline \multirow{2}{*}{$\begin{array}{l}\text { Thoracic completeness of } \\
\text { cytoreduction (CC) }\end{array}$} & $\mathrm{CCO}$ & 5 \\
\hline & $\mathrm{CC} 1$ or above & 1 \\
\hline \multirow{2}{*}{$\begin{array}{l}\text { Concurrent abdominal PMP at time } \\
\text { of thoracic CRS + HITHOC }\end{array}$} & Number & 4 \\
\hline & Concomitant abdominal CRS + HIPEC & 2 \\
\hline \multirow{4}{*}{$\begin{array}{l}\text { Further treatment post thoracic } \\
\text { CRS + HITHOC }\end{array}$} & Abdominal disease recurrence & 5 \\
\hline & Abdominal CRS + HIPEC & 5 \\
\hline & Thoracic disease recurrence & 1 \\
\hline & Thoracic CRS + HITHOC & 1 \\
\hline
\end{tabular}

CRS: Cytoreductive Surgery, HITHOC: Heated Intrathoracic Chemotherapy, PMP Pseudomyxoma peritonei.

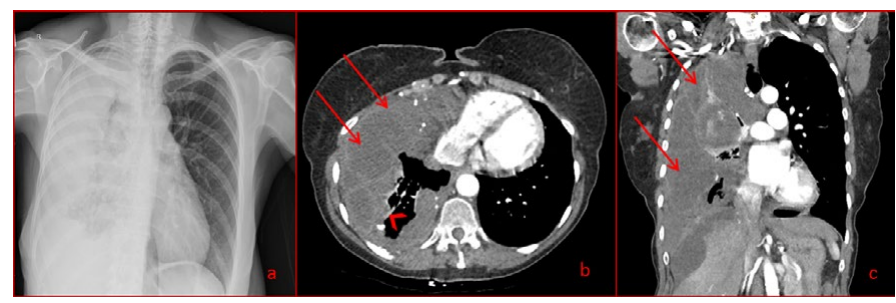

Figure 1. Chest X-ray (a) and chest computed tomography (b and c) demonstrating almost complete obliteration of the right lung by mucinous fluid accumulating in the right hemithorax. The loculated mucinous pleural effusion of PMP (arrows) with thickened pleura (arrowhead).

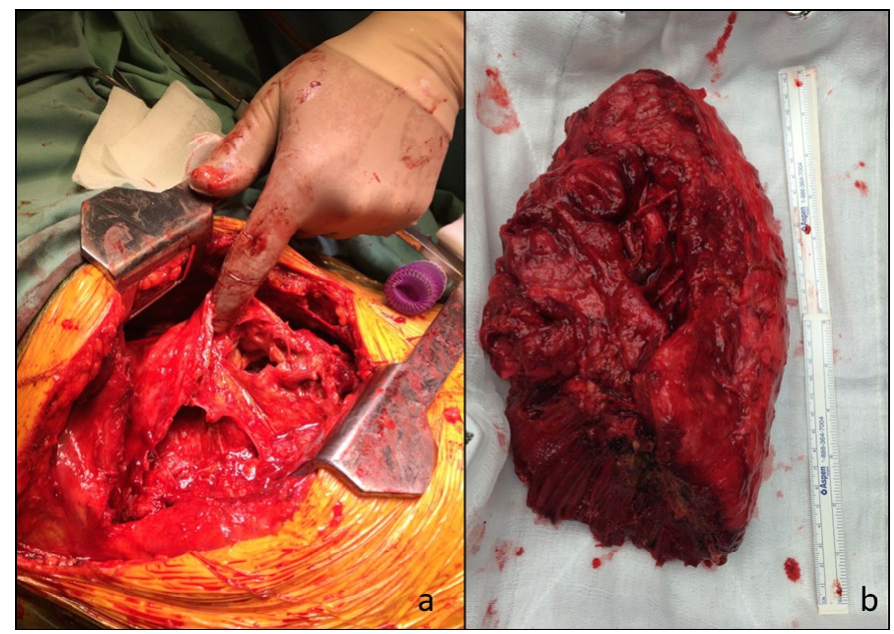

Figure 2. Thoracotomy identifying gelatinous material in thoracic cavity (a) and gross pneumonectomy specimen showing complete infiltration of affected lung by tumour material (b).

performed showed no evidence of neoplastic involvement. All patients had histological confirmation that the thoracic disease was identical to the previous abdominal mucinous tumour. 
Two patients recovered uneventfully and were discharged home with no complications. One patient required redo thoracotomy for evacuation of a haemothorax, and one patient experienced phrenic nerve palsy. The patient who underwent extra-pleural pneumonectomy had the longest hospital admission due to recurrent sepsis requiring a slow wean from ventilator support. She was discharged home 66 days after CRS with HITHOC. Her functional recovery has returned to nearbaseline and she has no evidence of thoracic or abdominal recurrence at 8 months follow up. The outcomes of all patients are recorded below (Table 2).

All patients with sufficient time since thoracic CRS and HITHOC were alive at 3 years follow up, while four of five patients were alive at 5 years. One of four patients was alive at 10-year follow up (Figure 3). No patients who received complete cytoreduction (CC0) developed pleural disease recurrence. One patient is awaiting radiofrequency ablation of a small lung nodule of undetermined aetiology.

\section{Discussion}

PMP is a disease that has previously generated some uncertainty regarding optimal treatment depending on its primary pathology $[8,9]$. CRS with HIPEC has demonstrated prolonged survival compared with debulking surgery alone, especially in DPAM. A 5-year survival rate of only $5 \%$ is offered to patients who undergo debulking surgery alone for PMP [10,11], while the addition of complete cytoreduction and HIPEC may permit 5 - and 10 -year survival rates over $75 \%$ in lowgrade disease [2,12-14]. Redo-CRS with HIPEC for disease recurrence has also demonstrated improvement in survival when compared with alternative treatments $[15,16]$.

The spread of PMP into the pleural cavity is rare and is commonly managed conservatively due to its inherent poor prognosis. However, similar to the treatment of abdominally contained PMP, complete cytoreduction and loco-regional chemotherapy can significantly improve overall mortality as well as disease-free survival. CRS via decortication, pleurectomy and/or pulmonary resection removes the bulk of the tumour burden, while the use of heated intrathoracic chemotherapy (HITHOC) provides maximal chemotoxic affects to remaining microscopic tumour while minimising systemic side effects. Survival from onset of intrathoracic extension without treatment is unknown. Due to the small number of cases and series in the literature, results from either debulking surgery alone or other palliative approaches are limited. However peri-operative and early results following CRS and HITHOC are favourable in the available results. Several case reports of intrathoracic spread of PMP discovered either during or following surgery for abdominal PMP, discuss treatment options including debulking surgery and systemic chemotherapy without HITHOC [17-21]. Survival outcomes are not reported in many cases, with most treatments aiming for palliation. However Pestieau and colleagues describe a series of 23 treated with CRS and HITHOC using Mitomycin $\mathrm{C}$ after developing intrathoracic spread of PMP [10]. Four patients had combined abdomino-thoracic disease present at their initial CRS. Nineteen patients developed thoracic recurrence of PMP following previously-treated abdominal disease. No intraparenchymal lesions were encountered in their cohort. The median time to thoracic recurrence following abdominal CRS was 19 months. Four patients had disease free survival from $2-42$ months. 11 patients had combined abdomino-thoracic recurrence of PMP and received palliative systemic chemotherapy. Of note in their series, 12 patients had diaphragmatic penetration at the time of abdominal CRS. This breach of the peritoneal-pleural cavities was postulated to potentially contribute to the spread of malignant cells into the pleural cavity. However a further seven patients developed new thoracic recurrence despite no diaphragmatic breach during initial CRS.

The biology of PMP is such that the mucin-producing cells tend

Figure 3. Overall Survival from time of thoracic CRS + HITHOC.

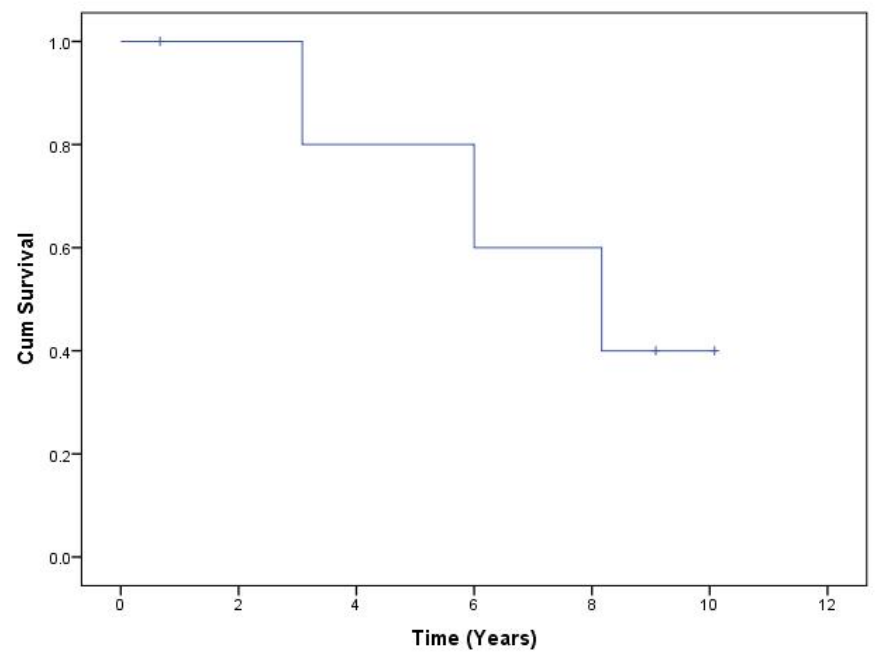

Kaplan-Meier graph for survival following thoracic cytoreductive surgery and heated intrathoracic chemotherapy for intrathoracic spread of pseudomyxomaperitonei. Overall 5 -year survival is $80 \%$ and 10 -year survival is $40 \%$.

Table 2. Outcomes following thoracic cytoreductive surgery and heated intrathoracic intraoperative chemotherapy for thoracic spread of Pseudomyxoma peritonei.

\begin{tabular}{|c|c|c|c|c|c|c|c|c|}
\hline Patient & Previous CRS & $\begin{array}{l}\text { Previous } \\
\text { HIPEC }\end{array}$ & Thoracic CRS & НITHOC & Cytoreduction & $\begin{array}{l}\text { Thoracic } \\
\text { recurrence }\end{array}$ & $\begin{array}{c}\text { Time since thoracic CRS } \\
+ \text { HITHOC }\end{array}$ & Status \\
\hline 1 & Abdominal CRS x 2 & $\mathrm{~N}$ & Lt pleurectomy and decortication & $\begin{array}{c}\text { mitomycin } \mathrm{C} \\
\text { 41.5deg for } 90 \text { mins }\end{array}$ & $\mathrm{CC} 0$ & $\mathrm{~N}$ & 72 months & DOD \\
\hline 2 & Abdominal CRS x 2 & $\mathrm{Y}$ & Lt pleurectomy and decortication & $\begin{array}{c}\text { mitomycin } \mathrm{C} \\
41.5 \mathrm{deg} \text { for } 90 \mathrm{mins}\end{array}$ & $\mathrm{CC} 0$ & $\mathrm{~N}$ & 109 months & AWD \\
\hline 3 & Abdominal CRS x 2 & $\mathrm{Y}$ & $\begin{array}{l}\text { Rt pleurectomy, decortication, wedge } \\
\text { resection Rt middle and lower lobe }\end{array}$ & $\begin{array}{c}\text { mitomycin } \mathrm{C} \\
\text { 41.5deg for } 90 \mathrm{mins}\end{array}$ & $\mathrm{CC} 0$ & $\mathrm{~N}$ & 121 months & AWD \\
\hline 4 & Abdominal CRS x 1 & $\mathrm{Y}$ & Bilat pleurectomy and decortication ${ }^{a}$ & $\begin{array}{c}\text { mitomycin } C \\
\text { 41.5deg for } 90 \text { mins }\end{array}$ & $\mathrm{CC} 1$ & $\mathrm{Y}$ & 98 months & DOD \\
\hline 5 & Abdominal CRS x 3 & $\mathrm{Y}$ & Rt middle and lower lobectomy & $\begin{array}{c}\text { mitomycin } \mathrm{C} \\
\text { 41.5deg for } 60 \mathrm{mins}\end{array}$ & $\mathrm{CCO}$ & $\mathrm{N}$ & 37 months & DOD \\
\hline 6 & Abdominal CRS x 1 & $\mathrm{~N}$ & Rt radical pneumonectomy & $\begin{array}{c}\text { mitomycin } \mathrm{C} \\
41.5 \mathrm{deg} \text { for } 90 \mathrm{mins}\end{array}$ & $\mathrm{CCO}$ & $\mathrm{N}$ & 8 months & NED \\
\hline
\end{tabular}

CRS: Cytoreductive Surgery, HITHOC: Heated Intrathoracic Chemotherapy, Lt: Left, Rt: Right, DOD: Died of Disease, AWD: Alive with Disease, NED: No Evidence of Disease ${ }^{a}$ CRS with HITHOC performed in right thorax initially, followed by CRS with HITHOC for left thorax disease subsequently discovered 
to gradually gather on peritoneal surfaces that absorb peritoneal fluid, such as the diaphragm and omentum [10,13,22,23]. Diaphragmatic involvement of PMP requires stripping of the mucinous tumour off the sub pleural surface to accomplish complete surgical cytoreduction. This can cause macro- and microscopic tears in the diaphragm and the central tendinous portion may be inadvertently or intentionally cut during surgery. Whole thickness diaphragmatic involvement may also necessitate diaphragmatic resection and reconstruction. This iatrogenically created communication between the abdomen and chest has been suggested as a means of spread of PMP from the abdomen to the pleural space. This may be the case in some instances, and some authors advocate this as the primary method of inter-cavity spread $[10,24,25]$. However two factors oppose this mechanism as the only cause of thoracic spread. First, there have been cases of intrathoracic spread without any previous diaphragmatic stripping or resection $[10,17,19,24,26]$ including our patient that required extra-pleural pneumonectomy (Table 2). Second, in our experience with abdominal PMP, any diaphragmatic defects are left open during the administration of HIPEC to allow all disease-affected tissue surfaces to be treated with regional chemotherapy. If the injury to the diaphragm created the only route of intrathoracic spread, it might be expected that many more cases of intrathoracic PMP would arise following CRS with HIPEC. This has not been shown in our series or in the available literature. Other suggested mechanisms on intra-pleural spread of PMP include the presence of congenital abdomino-pleural communications, and via lymphatic lacunae and hematologic spread to lung parenchyma $[10,22,25]$.

The most recent inclusion to our series is a 67 year-old female who had undergone previous debulking surgery for PMP 9 years earlier, with no diaphragmatic involvement identified at that time. She underwent radical pneumonectomy for extensive intrathoracic invasion of PMP. Complete cytoreduction was achieved and combined HIPEC/HITHOC was performed via the ipsilateral affected diaphragm being resected and reconstructed following loco-regional chemotherapy administration. Her postoperative course was complicated by empyema requiring repeat thoracotomy and washout, although the bronchial stump remained intact. This is the only reported case of pneumonectomyradical or otherwise- for PMP in the literature. This may be due to patients with such extensive disease being offered palliative treatments only. However the tumour biology of DPAM is such that growth is slow, potentially allowing compensatory mechanisms to maintain homeostasis. It is likely that the affected lung was functionally inactive prior to surgery given the extensive tumour involvement (Figure 1 and 2 ), and pneumonectomy therefore would not significantly change the amount of physiologically-active lung parenchyma. Despite a long period of weaning from ventilator support and long hospital stay, this patients' overall function returned to pre-operative status 6 months after surgery, with a functional capacity of approximately 3 metabolic equivalents (METS).

The intraoperative administration of HITHOC may add to the already established risks of single lung ventilation and pleural decortication and/or parenchymal resection. Cardiac and pulmonary toxicity are known complications of Mitomycin C use, although normally dependent on plasma exposure. Pulmonary oedema, interstitial pneumonitis and cardiomyopathy can occur following the intravenous administration of Mitomycin C. The intra-pleural perfusion with HITHOC might seem to offer an increased risk of complications occurring following major thoracic surgery, considering the close proximity of the heart and direct contact of the lung with the chemoperfusate. However in both our series and the available literature, this has not been demonstrated.

There have been several studies evaluating CRS and HITHOC for other pleural malignancies such as mesothelioma. The same principles of therapy as PMP treatment apply in that complete cytoreduction of the tumour is followed by HITHOC with the aim of macro- and microscopic tumour eradication. While survival and disease recurrence differs due to the differing pathology, very few direct chemotherapyrelated complications were observed in all reports. ICU and total hospital length of stay were 1-3 days and approximately 3 weeks respectively. Our centre has performed thoracic CRS + HITHOC with platin-based chemotherapy for mesothelioma in only 4 patients. There were no perioperative mortalities and repeat procedures have been performed for recurrence. Long term follow-up data was incomplete. In published studies, complete cytoreduction does appear to be a significant predictor of short and long-term outcomes for patients, regardless of pathology.

\section{Conclusion}

PMP has the potential to spread to both pleural and pulmonary tissues worsening the prognosis compared to isolated abdominal disease. Complete cytoreduction and HITHOC provides patients with the potential for long-term disease free survival with acceptable perioperative morbidity and mortality. This study reiterates the feasibility of CRS with HITHOC to achieve long-term disease-free and overall survival for thoracic recurrence of PMP. Large anatomical resections such as radical pneumonectomy and HITHOC can be performed however perioperative morbidity and mortality will be at least as high as pneumonectomy when performed for other malignancies. If complete cytoreduction can be achieved patients should be considered for this CRS and HITHOC only after thorough multidisciplinary review from centres with extensive experience with CRS and loco-regional chemotherapy for PMP.

\section{Acknowledgements}

We wish to thank Jing Zhao for the ongoing maintenance of the peritonectomy registry.

\section{References}

1. Chua TC, Moran BJ, Sugarbaker PH, Levine EA, Glehen O, et al. (2012) Earlyand Long-Term Outcome Data of Patients With Pseudomyxoma Peritonei From Appendiceal Origin Treated by a Strategy of Cytoreductive Surgery and Hyperthermic Intraperitoneal Chemotherapy. J Clin Oncol 30: 2449-2456. [Crossref]

2. Alzahrani N, Ferguson JS, Valle SJ, Liauw W, Chua T, et al. (2015)Cytoreductive surgery and hyperthermicintraperitoneal chemotherapy: long-term results at St George Hospital, Australia. ANZ J Surg. [Crossref]

3. Halabi El H, Gushchin V, Francis J, Athas N, Macdonald R, et al. (2012) The role of cytoreductive surgery and heated intraperitoneal chemotherapy (CRS/HIPEC) in patients with high-grade appendiceal carcinoma and extensive peritoneal carcinomatosis. Ann Surg Oncol 19: 110-114. [Crossref]

4. Iversen LH, Rasmussen PC, Hagemann-Madsen R, Laurberg S (2013)Cytoreductive surgery and hyperthermicintraperitoneal chemotherapy for peritoneal carcinomatosis: the Danish experience. Colorectal Dis 15: e365-372. [Crossref]

5. Yan TD, Links M, Xu ZY, Kam PC, Glenn D, et al. (2006) Cytoreductive surgery and perioperative intraperitoneal chemotherapy for pseudomyxomaperitonei from appendiceal mucinous neoplasms. Br J Surg 93: 1270-1276. [Crossref]

6. Kocsis A, Markóczy Z, Agócs L, Molnár M, Fillinger J, et al. (2012) [Pseudomyxoma of the pleura and of the peritoneum -- case report of a rare disease]. Magy Seb 65: 2426. [Crossref]

7. Senthil M, Harrison LE (2009) Simultaneous bicavitaryhyperthermicchemoperfusion in the management of pseudomyxomaperitonei with synchronous pleural extension. Arch Surg 144:970-972. [Crossref] 
8. Faris JE, Ryan DP (2013) Controversy and consensus on the management of patients with pseudomyxomaperitonei. Curr Treat Options Oncol 14: 365-373. [Crossref]

9. Moran B, BarattiD, Yan TD, Kusamura S, Deraco M (2008) Consensus statement on the loco-regional treatment of appendiceal mucinous neoplasms with peritoneal dissemination (pseudomyxomaperitonei). J Surg Oncol 98: 277-282. [Crossref]

10. Pestieau SR, Esquivel J, Sugarbaker PH (2000) Pleural extension of mucinous tumor in patients with pseudomyxomaperitonei syndrome. Ann Surg Oncol 7: 199-203. [Crossref]

11. Gough DB, Donohue JH, Schutt AJ, Gonchoroff N, Goellner JR, et al. (1994) Pseudomyxomaperitonei. Long-term patient survival with an aggressive regional approach. Ann Surg 219: 112-119. [Crossref]

12. Baratti D, Kusamura S, Nonaka D, Cabras AD, Laterza B, et al. (2009) Pseudomyxomaperitonei: biological features are the dominant prognostic determinants after complete cytoreduction and hyperthermicintraperitoneal chemotherapy. Ann Surg 249: 243-249. [Crossref]

13. Bevan KE, Mohamed F, Moran BJ (2010) Pseudomyxomaperitonei. World J Gastrointest Oncol 2: 44-50. [Crossref]

14. Vaira M, Cioppa T, DE Marco G, Bing C, D'Amico S, et al. (2009) Management of pseudomyxomaperitonei by cytoreduction+HIPEC (hyperthermicintraperitoneal chemotherapy): results analysis of a twelve-year experience. In Vivo 23: 639-644. [Crossref]

15. Votanopoulos KI, Ihemelandu C, Shen P, Stewart JH, Russell GB, et al. (2012) Outcomes of repeat cytoreductive surgery with hyperthermicintraperitoneal chemotherapy for the treatment of peritoneal surface malignancy. J Am Coll Surg 215: 412-417. [Crossref]

16. Sardi A, Jimenez WA, Nieroda C, Sittig M, MacDonald R, et al. (2013) Repeated cytoreductive surgery and hyperthermicintraperitoneal chemotherapy in peritoneal carcinomatosis from appendiceal cancer: Analysis of survival outcomes. EurJ Surg Oncol 39: 1207-1213. [Crossref]
17. Radosavljevic G, Nedeljkovic B, Kacar V (1993) Pseudomyxoma of the pleural and peritoneal cavities. Thorax 48: 94-95. [Crossref]

18. Lee BY, Kim HS, Lee SH, Moon HS, Cho SM, et al. (2004) Pseudomyxomaperitonei: extraperitoneal spread to the pleural cavity and lung. J Thorac Imaging 19: 123-126. [Crossref]

19. Mortman KD, Sugarbaker PA, Shmookler BM, DeGuzman VC, Soberman MS (1997) Pulmonary metastases in pseudomyxomaperitonei syndrome. Ann Thorac Surg 64: 1434-1436. [Crossref]

20. Peek DF, Beets GL (1999) Pseudomyxomaperitonei in the pleural cavity: report of a case. Dis Colon Rectum 42: 113-115. [Crossref]

21. Khan AA, Tambiah J, Cane P, Lang-Lazdunski L (2007) Prolonged survival in a patient with recurrent pulmonary metastases secondary to mucinous cystadenocarcinoma of the appendix with pseudomyxomatousperitonei. Ann Thorac Surg 83: 1893-1894. [Crossref]

22. Carmignani CP, Sugarbaker TA, Bromley CM, Sugarbaker PH (2003) Intraperitoneal cancer dissemination: mechanisms of the patterns of spread. Cancer Metastasis Rev 22: 465-472.[Crossref]

23. Sugarbaker PH (1994) Pseudomyxomaperitonei. A cancer whose biology is characterized by a redistribution phenomenon. Ann Surg 219: 109-111. [Crossref]

24. Kitai T (2012) Pulmonary metastasis from pseudomyxomaperitonei. Gastroenterol Res Pract 2012: 690256. [Crossref]

25. Chua TC, Yan TD, Yap ZL, Horton MD, Fermanis GG, et al. (2009) Thoracic cytoreductive surgery and intraoperative hyperthermicintrathoracic chemotherapy for pseudomyxomaperitonei. J Surg Oncol 99: 292-295. [Crossref]

26. Geisinger KR, Levine EA, Shen P, Bradley RF (2007) Pleuropulmonary involvement in pseudomyxomaperitonei: morphologic assessment and literature review. Am J Clin Pathol 127: 135-143. [Crossref]

Copyright: $(02016$ Doyle MP. This is an open-access article distributed under the terms of the Creative Commons Attribution License, which permits unrestricted use, distribution, and reproduction in any medium, provided the original author and source are credited. 